\title{
Probing the Accessible Sites for $n$-Butene Skeletal Isomerization over Aged and Selective H-Ferrierite with $d_{3}$-Acetonitrile
}

\author{
Sander van Donk, Eveline Bus, Alfred Broersma, Johannes H. Bitter, and Krijn P. de Jong ${ }^{1}$ \\ Department of Inorganic Chemistry and Catalysis, Debye Institute, Utrecht University, P.O. Box 80083, 3508 TB Utrecht, The Netherlands
}

Received May 7, 2002; revised July 4, 2002; accepted July 4, 2002

\begin{abstract}
Aged H-ferrierite (H-FER) samples with different contents of deposits were prepared and studied under differential catalytic conditions in a tapered element oscillating microbalance. Subsequently, these samples were examined using infrared spectroscopy to determine the nature of carbonaceous deposits and probing the type and number of accessible sites with $d_{3}$-acetonitrile. From these results, for the first time, we have been able to calculate turnover frequencies (TOFs) for $n$-butene conversion and isobutene formation for both fresh and aged H-FER catalysts. It is observed that the deposition of carbonaceous species significantly lowers the number of accessible Brønsted sites. With short time on stream (TOS), cracking of the alkyl-aromatic deposits contributes to the overall isobutene production but simultaneously harms the selective catalytic action by inducing nonselective side reactions. With prolonged TOS these deposits become nonreactive and as a result the TOF drops, while isobutene is produced with high selectivity. It is demonstrated that at this stage no carbenium ions are detected, while Brønsted $\mathrm{OH}$ acid sites are still accessible for $d_{3}$-acetonitrile on the extensively aged and highly selective H-FER. This indicates that the latter sites are responsible for the selective catalytic conversion of $n$-butene into isobutene. (c) 2002 Elsevier Science (USA)

Key Words: $n$-butene skeletal isomerization; isobutene; $\mathrm{H}$ ferrierite; infrared spectroscopy; $d_{3}$-acetonitrile, Brønsted acid sites; carbenium ions; carbonaceous deposits; oscillating microbalance.
\end{abstract}

\section{INTRODUCTION}

Zeolites containing 10-membered-ring (MR) pores have proven to exhibit high selectivities for the skeletal isomerization of linear butenes into isobutene (1-4). The twodimensional zeolite $\mathrm{H}$-ferrierite (H-FER), for which 8-MR pores interconnect the 10-MR main channels, displays an exceptionally high selectivity and stability $(5,6)$. Nevertheless, the initial selectivity of H-FER is low, but increases with time onstream (TOS) when carbonaceous deposits largely fill the H-FER pores (4, 7-9). Over a fresh catalyst ${ }^{13} \mathrm{C}$-labeling experiments have proven that nonselective bimolecular reactions, i.e., dimerization followed by cracking, dominate the catalytic action. However, in the

\footnotetext{
${ }^{1}$ To whom correspondence should be addressed. Fax: +31 302511027. E-mail: K.P.deJong@chem.uu.nl.
}

same experiments it was established that over an aged catalyst with carbonaceous deposits present, the formation of isobutene occurs selectively and must take place via a different route $(8,10,11)$.

A number of authors $(10,12-15)$ therefore suggested a monomolecular reaction pathway, in which butene is isomerized over a plain Brønsted acid site of H-FER, to be the dominant reaction pathway for isobutene formation. The monomolecular formation of isobutene involves an energetically and thermodynamically highly unfavorable primary carbenium ion (16). Therefore, an alternative pathway that does not involve a primary carbenium ion was proposed by Guisnet et al. $(9,17,18)$. It was claimed that with prolonged TOS all Brønsted acid sites are inaccessible for reactants (18) and the creation of new highly active and selective sites was assumed to explain the enhanced isobutene selectivity. This so-called pseudo-monomolecular reaction pathway is thought to proceed over alkyl-aromatic tertiary carbenium ions that are captured inside the entrances of the zeolite pores.

In the current study the number and nature of the active sites available on aged H-FER catalysts are established and correlated with the catalytic performance in butene skeletal isomerization. Catalysis experiments are performed in a tapered element oscillating microbalance (TEOM), which resembles a downflow fixed-bed reactor and offers the possibility of quantitatively monitoring the formation of carbonaceous deposits in situ $(19,20)$. Several H-FER catalysts holding different amounts of deposits are evaluated and subsequently examined with infrared (IR) spectroscopy to probe the available active sites. $d_{3}$-Acetonitrile $\left(\mathrm{CD}_{3} \mathrm{CN}\right)$ is used as a probe molecule which is relatively small in size, as are the involved butene isomers.

In recent years $\mathrm{CD}_{3} \mathrm{CN}$ has been widely employed in IR spectroscopic studies (21-28) because of its intermediate proton affinity (29) and the specific and high sensitivity of its $v(\mathrm{CN})$ stretching mode for interactions with different acid sites present in zeolites. Besides the ability to probe Brønsted and Lewis acid sites, Bystrov (21) and Jolly et al. (23) reported that $\mathrm{CD}_{3} \mathrm{CN}$ could be used to probe secondary and tertiary carbenium ions. This makes it a highly interesting probe molecule for studying the nature 
of the active sites for isobutene formation on aged H-FER catalysts to be either Brønsted acidic protons or carbenium ions prefixed in the coke. Hence, by elucidating the nature and number of the active and selective sites and correlating this with catalysis, this study contributes to the longstanding discussion whether zeolite protons or carbenium ions are the active centers for butene skeletal isomerization over aged H-FER.

\section{EXPERIMENTAL}

\section{Catalysis Experiments in a TEOM}

Commercially available high-silicon- $\mathrm{NH}_{4}^{+}$ferrierite (Zeolyst Int., Si/Al 30) was activated in a dry nitrogen flow at $823 \mathrm{~K}$ for $12 \mathrm{~h}$ to obtain the $\mathrm{H}^{+}$ferrierite (H-FER). The fresh H-FER displayed an acid site concentration of $0.53 \mathrm{mmol} \mathrm{g}^{-1}$ as determined by temperature-programmed desorption-thermogravic analysis (TPD-TGA) using $n$ propylamine. Nitrogen physisorption/ $t$-plot analysis shows an external surface area of $42 \mathrm{~m}^{2} \mathrm{~g}^{-1}$ and a micropore volume of $0.132 \mathrm{ml} \mathrm{g}^{-1}$.

Catalytic conversion and selectivity were determined for H-FER samples holding different amounts of carbonaceous deposits. The measurements were executed in a TEOM (Rupprecht \& Pataschnik TEOM 1500 PMA) to monitor the uptake of carbonaceous deposits during catalysis, hence in situ. For a detailed description of the TEOM we refer to Hershkowitz and Madiara (19) and Chen et al. (20). The tapered element was loaded with 5-10 mg of H-FER particles $(90-150 \mu \mathrm{m})$. Quartz wool was used at the top and bottom of the catalyst bed to keep the particles firmly packed. Measurements were performed at $623 \mathrm{~K}$ and 1.3 bar. Mass flow controllers adjusted the incoming gas flows. Reaction products were analyzed online using a Shimadzu 17A gas chromatograph with a Chrompack PLOT capillary column (fused-silica $\mathrm{Al}_{2} \mathrm{O}_{3} / \mathrm{KCl}, 50 \mathrm{~m} \times 0.32 \mathrm{~mm}$ ) equipped with a flame ionization detector. Prior to testing, the samples were dried in situ in nitrogen at $623 \mathrm{~K}$. All mass changes were corrected for temperature and gas-density differences by performing blank runs over inert samples.

Table 1 lists the content of carbonaceous deposits, the TOS, the applied weight hourly space velocity (WHSV), and the catalytic performance of the aged H-FER. The
WHSV was varied by adjusting the pure $n$-butene gas flow (Hoek Loos, 1-butene, $\geq 99.5 \%$ ) to examine all samples at similar and low conversions $(<10 \mathrm{~mol} \%)$. Conversion is defined as the change in mol\% of linear butenes when comparing the feed to the product mixture. Selectivities are calculated as the molar ratio of a certain product to all products $(\neq n$-butene). Immediately after the catalytic experiment the $n$-butene flow was switched off, and after cooling down, the catalyst was unloaded from the microbalance and subsequently studied by infrared spectroscopy, probing the active sites with $\mathrm{CD}_{3} \mathrm{CN}$. Check experiments were performed which showed that the aged H-FER samples maintained their catalytic performance after being cooled to room temperature under nitrogen, exposed to air, and subsequently reheated to the applied reaction temperature; this appeared to be the case for all samples. Moreover, nitrogen physisorption $/ t$-plot analysis for the extensively aged H-FER6.8C shows an external surface area of $19 \mathrm{~m}^{2} \mathrm{~g}^{-1}$ and a micropore volume of $0.013 \mathrm{ml} \mathrm{g}^{-1}$.

\section{IR Spectroscopy: Probing with $\mathrm{CD}_{3} \mathrm{CN}$}

FT-IR spectroscopy was performed using a Perkin Elmer Spectrum One instrument equipped with an in situ flow cell and an MCT detector. Measurements were performed on a fresh H-FER sample and on the aged H-FER samples listed in Table 1. A self-supported wafer of approximately $3 \mathrm{mg}$ with a diameter of $0.5 \mathrm{~cm}$ was prepared by applying a pressure of $200 \mathrm{MPa}$. The wafer was placed in a cylindrical oven and preheated to $623 \mathrm{~K}$ (the reaction temperature applied in the catalysis measurements) in a helium flow $\left(10 \mathrm{ml} \mathrm{min}^{-1}\right)$. Subsequently, the sample was cooled to $448 \mathrm{~K}$ and the adsorption of $\mathrm{CD}_{3} \mathrm{CN}$ (Acros, $99 \%$ purity) was started by switching the infrared cell inlet to a stream of $\mathrm{CD}_{3} \mathrm{CN}$ (partial pressure 5-10 mbar) in He $\left(10 \mathrm{ml} \mathrm{min}^{-1}\right)$. The applied conditions were assessed based on experimental examination, revealing the highest possible temperature and lowest partial pressure at which the maximum number of Brønsted acid sites is probed. Spectra were measured in transmission mode from 4000 to $1000 \mathrm{~cm}^{-1}\left(4 \mathrm{~cm}^{-1}\right.$ resolution) and after background subtraction (spectrum of the empty cell) normalized to the overtone lattice vibration of H-FER between 1880 and $1860 \mathrm{~cm}^{-1}(A=0.3)$, which is a good measure of the thickness of the wafer. To quantify the

TABLE 1

Carbon Uptake, TOS, WHSV, and Catalytic Performance of the Aged H-FER Samples at $623 \mathrm{~K}$

\begin{tabular}{|c|c|c|c|c|c|}
\hline \multirow[b]{2}{*}{ Sample } & \multicolumn{2}{|c|}{ Reaction conditions } & \multicolumn{3}{|c|}{ Results uptake and catalytic performance } \\
\hline & $\begin{array}{l}\text { TOS } \\
\text { (h) }\end{array}$ & $\begin{array}{c}\text { WHSV } \\
\left(\mathrm{g}_{\mathrm{C} 4=} \mathrm{g}_{\mathrm{H}-\mathrm{FER}}{ }^{-1} \mathrm{~h}^{-1}\right)\end{array}$ & $\begin{array}{c}\text { Carbon uptake } \\
\left(100 \mathrm{~g}_{\text {uptake }} \mathrm{g}_{\mathrm{H}-\mathrm{FER}}{ }^{-1}\right)\end{array}$ & $\begin{array}{l}n \text {-Butene conversion } \\
(\mathrm{mol} \%)\end{array}$ & $\begin{array}{l}\text { Isobutene selectivity } \\
(\mathrm{mol} \%)\end{array}$ \\
\hline H-FER5.0C & 4 & 169 & 5.0 & 9.5 & 35.5 \\
\hline H-FER6.6C & 20 & 142 & 6.6 & 8.9 & 38.0 \\
\hline H-FER6.8C & 300 & 21 & 6.8 & 8.5 & 91.2 \\
\hline
\end{tabular}


amount of $\mathrm{CD}_{3} \mathrm{CN}$ adsorbed on the Brønsted sites of the sample, the $v(\mathrm{CN})$ stretch region $\left(2600-2100 \mathrm{~cm}^{-1}\right)$ was integrated after deconvolution using the Origin 6.1 software program. The extinction coefficients for all samples were assumed to be similar.

\section{RESULTS}

\section{Catalysis Experiments in a TEOM}

The results of the catalytic experiments performed in the TEOM on H-FER samples holding different amounts of carbonaceous deposits are collected in Table 1. Results have been obtained under differential conditions at low $(<10 \mathrm{~mol} \%)$ and similar conversions to compare the catalytic behavior of the aged H-FER samples in a quantitative way. Both H-FER5.0C and H-FER6.6C, measured at 4 and $20 \mathrm{~h}$ TOS, respectively, display low selectivities toward isobutene of around $37 \mathrm{~mol} \%$. For the extensively aged H-FER6.8C obtained at $300 \mathrm{~h}$ TOS, the isobutene selectivity is drastically enhanced to $91 \mathrm{~mol} \%$. This is an important feature since only a minor increase in uptake of carbonaceous deposits occurred from H-FER6.6C to H-FER6.8C. Hence, the major increase in selectivity cannot be directly related to the amount of carbonaceous deposits.

\section{IR Spectroscopy: Probing Fresh H-FER with $\mathrm{CD}_{3} \mathrm{CN}$}

The fresh H-FER sample was studied with IR spectroscopy by probing the active sites in situ with $\mathrm{CD}_{3} \mathrm{CN}$. Figure 1 shows the IR spectra of fresh H-FER, of H-FER with adsorbed $\mathrm{CD}_{3} \mathrm{CN}$, and the difference of these two spectra. The fresh H-FER spectrum displays a peak at $3742 \mathrm{~cm}^{-1}$ corresponding to the $\mathrm{OH}$ stretch vibration of the terminal silanol groups $(30,31)$ which are mainly located on the external surfaces of the H-FER crystals. The band around $3580 \mathrm{~cm}^{-1}$ is built of different $\mathrm{Br} \varnothing \mathrm{nsted} \mathrm{OH}$ groups that are bridged between silicon and aluminum cations present in

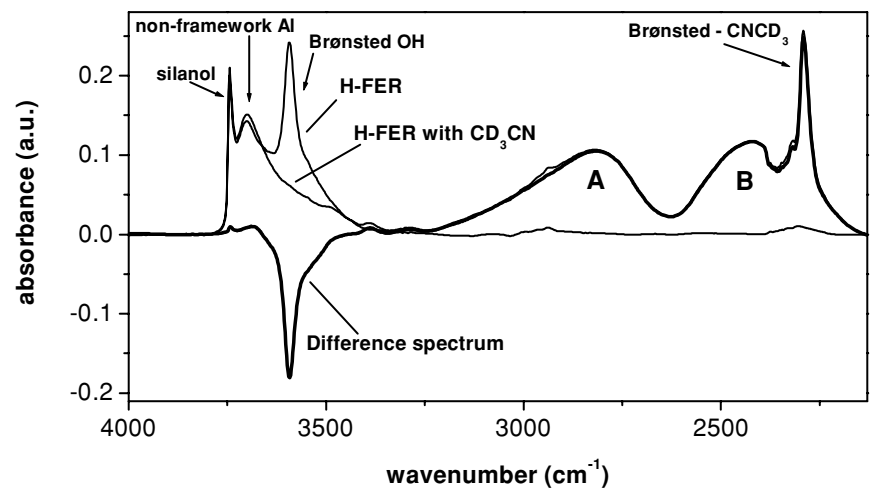

FIG. 1. IR spectra of H-FER, H-FER with adsorbed $\mathrm{CD}_{3} \mathrm{CN}$, and the difference spectrum, obtained at 5 mbar $\mathrm{CD}_{3} \mathrm{CN}$ pressure in $10 \mathrm{ml} \mathrm{min}^{-1}$ He flow, $T=448 \mathrm{~K}$.

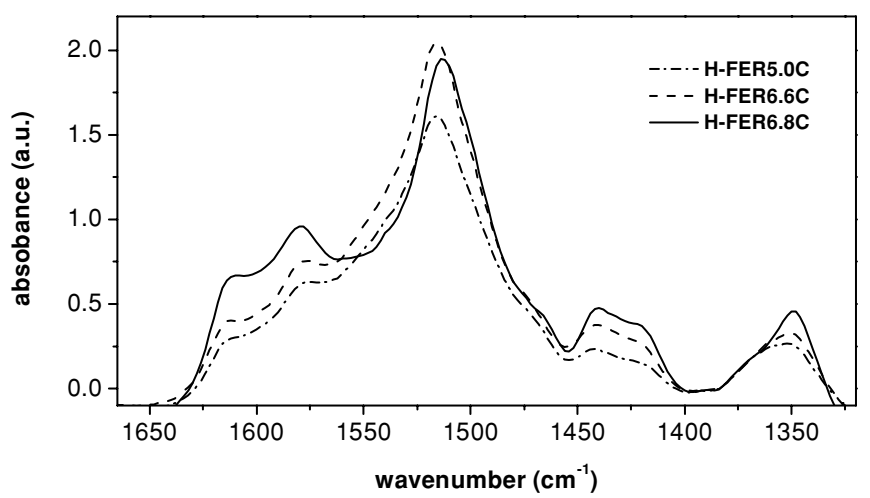

FIG. 2. IR spectra of the carbonaceous deposits on H-FER5.0C, HFER6.6C, and H-FER6.8C. The spectra are obtained under a $10 \mathrm{ml} \mathrm{min}^{-1}$ He flow, $T=623 \mathrm{~K}$, and the spectrum of the dried H-FER (without deposits) is subtracted.

the H-FER structure $(30,31)$. A band around $3700 \mathrm{~cm}^{-1}$ (32) indicates the presence of nonframework aluminum species.

The spectrum after $\mathrm{CD}_{3} \mathrm{CN}$ adsorption displayed in Fig. 1 shows the generally established A and B contours (22, 24, 25,28 ) present at $\sim 2820$ and $\sim 2420 \mathrm{~cm}^{-1}$, respectively, resulting from a large red shift of $v(\mathrm{OH})$ due to moderate hydrogen bonding to the $\mathrm{CD}_{3} \mathrm{CN}$ nitrogen $(22,25)$. The peak at $2292 \mathrm{~cm}^{-1}$ is assigned to the stretch vibration of $\nu(\mathrm{CN})$ coordinated to a Brønsted acid site (22-28). A very small number of Lewis acid sites are also covered at the applied $\mathrm{CD}_{3} \mathrm{CN}$ pressure, which results in a small shoulder at $2318 \mathrm{~cm}^{-1}(22,24,25,27,28)$. Minor disappearance of the silanol peak at $3742 \mathrm{~cm}^{-1}$ occurs and, accordingly, no peak of the stretch vibration of $v(\mathrm{CN})$ coordinated to a silanol group is observed, which if present should be around $2275 \mathrm{~cm}^{-1}(22,25,27,28)$.

\section{IR Spectroscopy: Probing Aged H-FER with $\mathrm{CD}_{3} \mathrm{CN}$}

After the catalysis, the aged H-FER samples were studied with IR spectroscopy. In Fig. 2 the regions that characterize the carbonaceous species deposited on H-FER are displayed for all aged samples. The absorption at $1514 \mathrm{~cm}^{-1}$ corresponds to the carbon-carbon bond vibration of hydrogen-rich noncondensed aromatics $(18,33)$. However, by the appearance of additional bands around 1415,1578 , and $1610 \mathrm{~cm}^{-1}$, the presence of condensed aromatic deposits is indicated $(18,33)$. Moreover, the peak around $1420 \mathrm{~cm}^{-1}$ indicates the presence of cyclopentane ring structures. Two contributions can also be distinguished at 1442 and $1350 \mathrm{~cm}^{-1}$ that are characteristic for the bending modes of $\mathrm{CH}_{2}-$ and $\mathrm{CH}_{3}-$ aliphatic groups, respectively $(18,33,34)$. Going from H-FER5.0C to $\mathrm{H}-$ FER6.6C, Fig. 2 shows that all bands display a higher intensity due to the elevated content of deposits of the latter sample. Next, going from H-FER6.6C to H-FER6.8C, the 


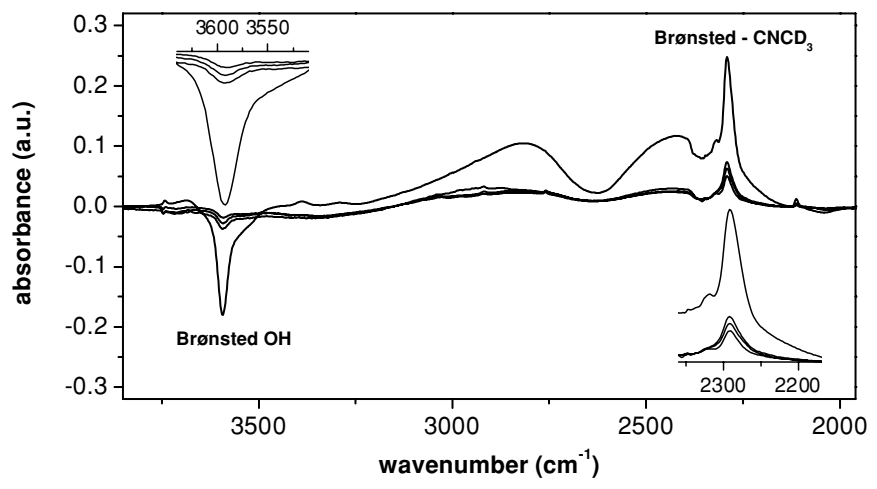

FIG. 3. IR difference spectra of $\mathrm{CD}_{3} \mathrm{CN}$ adsorbed on fresh $\mathrm{H}$ FER, H-FER5.0C, H-FER6.6C, and H-FER6.8C, obtained at 5-10 mbar $\mathrm{CD}_{3} \mathrm{CN}$ pressure in $10 \mathrm{ml} \mathrm{min}{ }^{-1}$ He flow, $T=448 \mathrm{~K}$. Negative peaks correspond to the disappearance and positive peaks to the appearance of a vibration. The figure insets display a close-up of the Brønsted $v(\mathrm{OH})$ stretch region (top left) and the $v(\mathrm{CN})$ stretch region (bottom right).

band at $1514 \mathrm{~cm}^{-1}$ slightly decreases while the bands that are characteristic for condensed aromatics clearly increase. Therefore these results suggest that with extensive aging of H-FER the nature of carbonaceous deposits changes toward less-hydrogen-rich species. In combination with the bands characteristic for cyclopentane and alkyl groups it is suggested that with prolonged TOS condensed cyclopentafused alkyl-aromatic ring structures are present on the catalyst, which is in perfect agreement with results from Guisnet et al. (18).

Subsequently the aged H-FER samples were probed in situ with $\mathrm{CD}_{3} \mathrm{CN}$ so that the number and nature of active sites were established. In Fig. 3 the difference spectra, i.e., the difference between the spectra with and without $\mathrm{CD}_{3} \mathrm{CN}$, are shown for fresh H-FER and for the differently aged H-FER samples. Upon adsorption of $\mathrm{CD}_{3} \mathrm{CN}$ the band assigned to the Brønsted acid sites at $3580 \mathrm{~cm}^{-1}$ becomes negative, which illustrates the disappearance of Brønsted acid sites. For all samples it is observed that the disappearance of the Brønsted peak correlates with the appearance of the peak at $2292 \mathrm{~cm}^{-1}$. Hence, the positive peak at $2292 \mathrm{~cm}^{-1}$ can be solely assigned to the stretch vibration of $v(\mathrm{CN})$ coordinated to a Brønsted acid site, which was also observed in other studies (22-28). With increasing amounts of carbonaceous deposits, the difference peak corresponding to the Brønsted sites becomes less negative and the difference peak for adsorbed $\mathrm{CD}_{3} \mathrm{CN}$ becomes less positive. This indicates that the number of Brønsted acid sites that are accessible for $\mathrm{CD}_{3} \mathrm{CN}$ is reduced upon $n$-butene reaction. Nevertheless it is clear that Brønsted acid sites are still accessible, even for the extensively aged H-FER6.8C sample. In Fig. 4 the IR spectrum of H-FER6.8C with adsorbed $\mathrm{CD}_{3} \mathrm{CN}$ is displayed and, as a comparison, the spectrum of $\mathrm{CD}_{3} \mathrm{CN}$ adsorbed on fresh H-FER is also shown. In the H-FER6.8C spectrum a small Brønsted band remains after

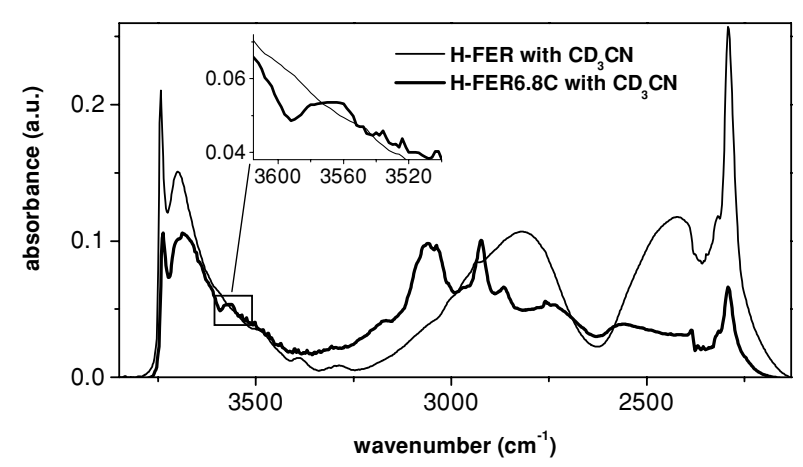

FIG. 4. IR spectra of $\mathrm{H}-\mathrm{FER}$ and $\mathrm{H}-\mathrm{FER} 6.8 \mathrm{C}$ with adsorbed $\mathrm{CD}_{3} \mathrm{CN}$, obtained at 5 mbar $\mathrm{CD}_{3} \mathrm{CN}$ pressure in $10 \mathrm{ml} \mathrm{min}{ }^{-1} \mathrm{He}$ flow, $T=448 \mathrm{~K}$. The figure inset illustrates the peak for the unperturbed Brønsted sites on $\mathrm{H}$-FER6.8C that remains after $\mathrm{CD}_{3} \mathrm{CN}$ probing.

$\mathrm{CD}_{3} \mathrm{CN}$ adsorption, which reveals that some Brønsted acid sites remain unperturbed upon probing, indicating that not all sites are accessible. The maximum of the small band that remains after probing is located at slightly lower frequencies $\left(\sim 3560 \mathrm{~cm}^{-1}\right)$ than the peak maximum observed for fresh H-FER ( $3580 \mathrm{~cm}^{-1}$, see Fig. 1$)$.

The specific and high sensitivity of the $v(\mathrm{CN})$ stretching mode at $2292 \mathrm{~cm}^{-1}$ allows quantification of the accessible Brønsted acid sites present in the aged H-FER samples. In Table 2 the peak areas relative to the peak area of the fresh H-FER and the numbers of accessible Brønsted acid sites for the different H-FER samples are displayed. The number of accessible Brønsted acid sites for fresh H-FER was determined to be $0.53 \mathrm{mmol} \mathrm{g}^{-1}$ using $n$-propylamine TPD-TGA. For the aged H-FER samples the numbers of accessible Brønsted acid sites are calculated by taking the ratio of $\mathrm{CD}_{3} \mathrm{CN}$ peak areas of aged and fresh H-FER and multiplying the outcome with the number determined for fresh H-FER. Hence, a large reduction in the number of accessible Brønsted acid sites is observed for the aged H-FER samples upon $n$-butene reaction. For aged H-FER6.8C obtained with long TOS and containing a maximum amount

TABLE 2

$\mathrm{CD}_{3} \mathrm{CN}$ Peak Areas and Number of Accessible Brønsted Acid Sites

\begin{tabular}{lcc}
\hline \multicolumn{1}{c}{ Sample } & $\begin{array}{c}\text { Relative integrated } \\
\text { area of } \mathrm{CD}_{3} \mathrm{CN} \text { peak } \\
\text { at } 2292 \mathrm{~cm}^{-1}(\%)\end{array}$ & $\begin{array}{c}\text { Number of accessible } \\
\text { Brønsted acid sites } \\
\left(\mathrm{mmol} \mathrm{g}_{\mathrm{H}-\mathrm{FER}}{ }^{-1}\right)\end{array}$ \\
\hline H-FER & 100 & $0.530^{b}$ \\
H-FER5.0C & $25^{a}$ & $0.133^{c}$ \\
H-FER6.6C & $21^{a}$ & $0.111^{c}$ \\
H-FER6.8C & $14^{a}$ & $0.074^{c}$ \\
\hline
\end{tabular}

\footnotetext{
${ }^{a}$ Relative area normalized on the area for H-FER.

${ }^{b}$ Number of Brønsted acid sites of H-FER is determined by $n$ propylamine TPD-TGA.

${ }^{c}$ Number of Brønsted acid sites of aged H-FER $=\left(\right.$ area of $\mathrm{CD}_{3} \mathrm{CN}$ peak/100) $*$ number for H-FER.
} 
of coke, $14 \%$ of the original number of Brønsted acid sites are still accessible for $\mathrm{CD}_{3} \mathrm{CN}$. To determine whether the sites that are accessible for $\mathrm{CD}_{3} \mathrm{CN}$ are also accessible for $n$-butene, all H-FER samples were additionally probed with $n$-butene. The changes in the Brønsted acid region resulting from butene adsorption are in good agreement with the results obtained for $\mathrm{CD}_{3} \mathrm{CN}$, although quantification is not possible due to a large contribution of weakly sorbed butenes that partially overlaps with the Brønsted $\mathrm{OH}$ band.

Bystrov (21) and Jolly et al. (23) reported that the adsorption of $\mathrm{CD}_{3} \mathrm{CN}$ at low temperature on zeolite samples used in hydrocarbon conversions may result in the appearance of a sharp peak between 2387 and $2377 \mathrm{~cm}^{-1}$, which is characteristic for the vibration of $v(\mathrm{CN})$ bound to a carbocation. However, from Figs. 3 and 4 it is clear that no such contribution is observed and therefore most likely no carbenium ions are present on the aged H-FER samples after they were heated to $623 \mathrm{~K}$ (the reaction temperature), cooled to $448 \mathrm{~K}$ under a He flow, and then probed with $\mathrm{CD}_{3} \mathrm{CN}$. To further check the formation of carbenium ions as stable active sites in butene skeletal isomerization, H-FER has been aged in situ at $623 \mathrm{~K}$, cooled to $448 \mathrm{~K}$ under a He flow, and subsequently probed with $\mathrm{CD}_{3} \mathrm{CN}$ at different TOS. Also, in the spectra obtained during these experiments no peaks were observed in the $2387-2377 \mathrm{~cm}^{-1}$ region.

\section{Relation between Catalytic Performance and Brønsted Acidity}

The catalysis data presented in Table 1 indicate that with longer TOS lower WHSVs are demanded to obtain similar $n$-butene conversions, indicating that the H-FER sample becomes less active upon aging. By taking into account the applied WHSVs for the differently aged H-FER samples, reaction rates for both the conversion of $n$-butenes and the formation of isobutene are calculated and displayed in Table 3. Figure 5 displays these reaction rates as a function of the number of accessible Brønsted acid sites on the aged

TABLE 3

Reaction Rates and TOFs of the Aged H-FER Samples at $623 \mathrm{~K}$

\begin{tabular}{cccccc}
\hline & \multicolumn{2}{c}{$\begin{array}{c}\text { Reaction rates } \\
\left(\mathrm{g} \mathrm{g}_{\mathrm{H}-\mathrm{FER}}{ }^{-1} \mathrm{~h}^{-1}\right)\end{array}$} & & \multicolumn{2}{c}{$\begin{array}{c}\text { TOFs } \\
\left(\mathrm{mmol} \mathrm{mmol}^{-1} \mathrm{~h}^{-1}\right)\end{array}$} \\
\cline { 2 - 3 } \cline { 5 - 6 } Sample & $\begin{array}{c}n \text {-Butene } \\
\text { conversion }^{a}\end{array}$ & $\begin{array}{c}\text { Isobutene } \\
\text { formation }^{b}\end{array}$ & & $\begin{array}{c}n \text {-Butene } \\
\text { converted }^{c}\end{array}$ & $\begin{array}{c}\text { Isobutene } \\
\text { formed }^{c}\end{array}$ \\
\hline H-FER5.0C & 16.1 & 5.7 & & $21.6 \times 10^{2}$ & $7.7 \times 10^{2}$ \\
H-FER6.6C & 12.6 & 4.8 & & $20.3 \times 10^{2}$ & $7.7 \times 10^{2}$ \\
H-FER6.8C & 1.8 & 1.6 & & $4.3 \times 10^{2}$ & $3.9 \times 10^{2}$
\end{tabular}

\footnotetext{
${ }^{a}$ Rate $n$-butene conversion $=[($ WHSV $) *($ Conversion $)] / 100$.

${ }^{b}$ Rate isobutene formation $=[($ Rate $n$-butene conversion $) *($ isobutene selectivity)]/100.

${ }^{c} \mathrm{TOF}=($ rate $/ 56) /$ number of accessible Brønsted acid sites (see Table 2).
}

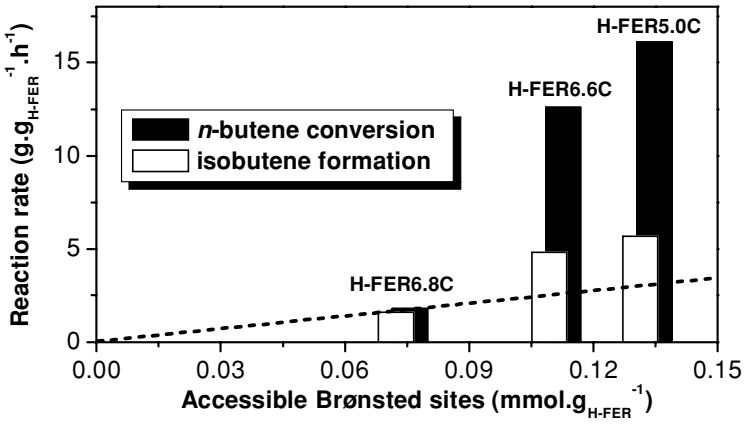

FIG. 5. Reaction rates for $n$-butene conversion and isobutene formation as a function of the number of accessible Brønsted acid sites on the aged H-FER samples, as probed by $\mathrm{CD}_{3} \mathrm{CN}$. The dashed line (- - -) indicates the expected reaction rates if catalysis on all samples occurs in linear correlation with the results obtained for H-FER6.8C and with the number of accessible Brønsted acid sites.

H-FER samples, as probed by $\mathrm{CD}_{3} \mathrm{CN}$ (see also Table 2). By considering this number of accessible Brønsted acid sites, the reaction rates of the aged H-FER samples can be transformed into TOFs. The TOFs for $n$-butene conversion and isobutene formation are also collected in Table 3, giving the moles of $n$-butenes converted or moles of isobutenes formed per mole accessible Brønsted acid site per hour.

\section{DISCUSSION}

\section{On the Number, Nature, and Location of the Active Sites}

The observed reduction in intensity of the $v(\mathrm{CN})$ peak at $2292 \mathrm{~cm}^{-1}$ (Fig. 3) with increasing content of carbonaceous deposits indicates that upon $n$-butene reaction the number of accessible Brønsted acid sites in H-FER decreases. On a fresh $\mathrm{H}$-FER the number of accessible Brønsted acid sites is $0.53 \mathrm{mmol} \mathrm{g}^{-1}$, while during $n$-butene reaction this number decreases for H-FER6.8C to a value of $0.074 \mathrm{mmol} \mathrm{g}^{-1}$, i.e., $14 \%$ of the initial value (Table 2 ). This agrees well with the decrease in micropore volume as determined by nitrogen physisorption going from $0.132 \mathrm{ml} \mathrm{g}^{-1}$ on the fresh H-FER to $0.013 \mathrm{ml} \mathrm{g}^{-1}$ on H-FER6.8C. The adsorption of $\mathrm{CD}_{3} \mathrm{CN}$ on the aged H-FER samples induces a large but not complete reduction of the band assigned to the Brønsted acid sites at $3580 \mathrm{~cm}^{-1}$, which is illustrated for H-FER6.8C in Fig. 4. This reveals that not all Brønsted acid sites in the aged H-FER sample are accessible for $\mathrm{CD}_{3} \mathrm{CN}$. Additionally, the maximum of the remaining Brønsted acid band for H-FER6.8C (Fig. 4) is shifted toward slightly lower frequencies compared to fresh H-FER (Fig. 1). Since it is known that the $\mathrm{OH}$ groups in the 8-MR pores absorb at lower wavenumbers than those in the $10-\mathrm{MR}$ channels $(30,31)$, the observed shift implies that upon $\mathrm{CD}_{3} \mathrm{CN}$ adsorption Brønsted sites remain vacant in the cages of the 8-MR pores. This indicates that with the formation of carbonaceous deposits at least part of the entrances of the 8-MR pores 
is blocked so that sites in these cages become inaccessible for both $\mathrm{CD}_{3} \mathrm{CN}$ and butenes. As a result, the Brønsted sites that are still accessible for $\mathrm{CD}_{3} \mathrm{CN}$ and butenes will be located predominantly in the 10-MR channels, implying that only these sites are involved in the catalytic action. This result is in excellent agreement with Wichterlova et al. (35) and Domokos et al. (31), who reported on the correlation between acid site locations in sodium-exchanged H-FER samples and their catalytic performances. In these studies a clear structure-activity relationship was observed between the presence of Brønsted acid sites in the 10MR channels and the selective formation of isobutene. In our study we show that this structure-activity relation also exists under full-catalysis conditions, i.e., when carbonaceous deposits fill a large part of the H-FER micropore volume.

In contrast with the results presented in our study, Guisnet et al. (18) claimed that on aged H-FER all Brønsted acid sites would be inaccessible for reactants on probing aged $\mathrm{H}-\mathrm{FER}$ with ammonia $\left(\mathrm{NH}_{3}\right)$ at $323 \mathrm{~K}$ under vacuum. However, if one looks more closely into the spectra of Guisnet et al. (18) a slight decrease in the Brønsted band is observed upon $\mathrm{NH}_{3}$ probing, indicating that at least a small number of Brønsted acid sites remains accessible after aging. This is, at least qualitatively, in agreement with the results obtained in the present study. The quantitative differences between the study of Guisnet et al. (18) and this study may be caused by selection of the probe molecule, the H-FER Si/Al ratio, and the applied experimental conditions like temperature and pressure.

Based on the assumption that Brønsted sites are unavailable for the catalytic action on aged H-FER, Guisnet et al. $(9,17,18)$ proposed that the enhancement of isobutene selectivity with TOS originated from the creation of alkylaromatic tertiary carbenium ions that are captured inside the entrances of the zeolite pores. Linear butenes would then react with these carbenium ions through a socalled pseudo-monomolecular reaction pathway in which a methyl and hydride shift followed by $\beta$-scission produces the isobutene. The present study does not reveal the presence of carbenium ions and, hence, the occurrence of a pseudo-monomolecular pathway seems less likely. This conclusion is supported by results of Mériaudeau et al. (36), who compared the skeletal isomerization of linear butenes and pentenes over aged H-FER. Their results demonstrated that $n$-pentene is isomerized much faster than $n$-butene. The observed difference in rates arises from the fact that the monomolecular skeletal isomerization of $n$-butene involves the formation of an energetically and thermodynamically highly unfavorable primary carbenium ion (16), while for $n$-pentene the monomolecular reaction occurs via a much more stable secondary carbenium ion. The experimentally observed rate difference indicates that the skeletal isomerization of both $n$-butene and $n$-pentene will probably not proceed via a pseudo-monomolecular reaction pathway, since then similar isomerization rates are expected.

\section{Relation between Catalytic Performance and Brønsted Acidity}

The reaction rates for $n$-butene conversion and isobutene formation decrease with increasing coke content and decreasing number of accessible Brønsted acid sites (see Table 3 and Fig. 5). However, no simple linear relationship is observed between the aged H-FER samples studied, which is indicated by the dashed line in Fig. 5. This is further emphasized by the fact that the TOFs in Table 3 are not the same for all three samples. Nevertheless, large similarity for both H-FER5.0C and H-FER6.6C is observed, which suggests that, despite their different contents in carbonaceous deposits, identical reactions are prevailing on these catalysts. This analogous behavior is further illustrated by their similar isobutene selectivities displayed in Table 1 . In contrast, the isobutene selectivity for the extensively aged H-FER6.8C is much higher and the TOFs are significantly lower than for H-FER5.0C and H-FER6.6C. Simultaneously, only a minor increase in deposits occurred, going from H-FER6.6C to H-FER6.8C. Hence, the major increase in isobutene selectivity and the drastic decreases in reaction rates are neither directly related to the amount of carbonaceous deposits nor to the number of Brønsted acid sites as already indicated in Fig. 5. Therefore, it becomes obvious that the nature of carbonaceous deposits largely affects the catalytic action and the dominant reaction pathway.

The nature of the deposits is deduced from the IR spectra of the carbon region as displayed in Fig. 2. The carbonaceous deposits change from alkyl-aromatic toward more condensed alkyl-aromatic species going from the shortly aged samples, i.e., H-FER5.0C and H-FER6.6C, to the extensively aged H-FER6.8C sample. This change in the nature of coke with TOS has been observed before in other studies $(7,8,33)$. In general hydrogen-rich carbonaceous deposits are more reactive than hydrogen-poor ones and, hence, cracking reactions of such reactive deposits will likely cause the higher TOF values for H-FER5.0C and H-FER6.6C in Table 3. The discrepancies between the TOFs of $n$-butene converted and isobutene formed clearly indicate that these reactions are not predominantly selective toward isobutene formation and additionally form byproducts, resulting in low isobutene selectivities (Table 1). This agrees very well with ${ }^{13} \mathrm{C}$-labeling studies performed at short TOS $(8,10,11)$, where it was suggested that with short TOS mainly nonselective bimolecular reactions dominate the catalytic action.

For H-FER6.8C, however, the reactivity of deposits and concomitant appearance of by-products are significantly reduced, resulting in a lower TOF for the conversion of 
$n$-butene. Furthermore, the similar TOF for the formation of isobutene indicates the high isobutene selectivity observed for H-FER6.8C. This again correlates to the ${ }^{13} \mathrm{C}$ labeling experiments $(8,10,11)$, in which it was observed that with extensive aging of the catalyst a change in the prevailing reaction pathway for the formation of isobutene occurred.

When we assume that the catalytic action on H-FER6.8C runs predominantly over the Brønsted acid sites available, the dashed line in Fig. 5 now indicates that half of the isobutenes obtained for H-FER5.0C and H-FER6.6C originate from reactions other than the selective one running over Brønsted acid sites. The reactive carbonaceous deposits present on the mildly aged H-FER5.0C and H-FER6.6C likely induce such nonselective reactions. The suggestion that reactive deposits take part in the nonselective catalytic action agrees with earlier work of Xu et al. (7) and Finelli et al. (33).

Asensi et al. (14) showed that on a high-silica H-FER $(\mathrm{Si} / \mathrm{Al}=59$, i.e., low numbers of Brønsted acid sites) high isobutene selectivities were reached without the substantial formation of deposits. Recently, an extensive kinetic study by Domokos et al. (37) confirmed that the presence of deposits is not crucial for achieving high isobutene selectivities and that isobutene is likely formed over Brønsted acid sites. However, it must be noted that at atmospheric or higher pressures, i.e., under conditions that are closer to industrial ones, the deposition of carbonaceous species cannot be avoided, as was shown by the group at Shell $(6,8)$ and is demonstrated in Table 1 and Fig. 2. During the complete catalytic action, the role of these deposits is rather ambiguous. According to Fig. 3 the deposition of carbonaceous species lowers the amount and density of accessible Brønsted sites, consequently suppressing nonselective bimolecular reactions. Nevertheless, the deposition of reactive species significantly contributes to the overall product formation, although not at all selectively since, besides isobutene, numerous by-products are formed. With extensive aging of H-FER, the high isobutene selectivity mainly stems from the fact that carbonaceous deposits have become nonreactive and $n$-butene is now exclusively transformed over the Brønsted acid sites left on aged $\mathrm{H}$ FER. Additional effects like preferential deactivation of nonselective acid sites and/or a decrease in Brønsted acid site concentration as suggested by others $(3,7,13,15,35)$ may also contribute to the enhanced performance of aged H-FER.

\section{CONCLUSIONS}

Catalytically active H-FER samples with different amounts of deposits were prepared and studied under differential catalytic conditions in a TEOM. Subsequently, these samples were examined by IR spectroscopy to unravel the nature of carbonaceous deposits, and the number of accessible Brønsted acid sites was probed using $\mathrm{CD}_{3} \mathrm{CN}$. The deposition of carbonaceous species significantly lowers the number of accessible Brønsted sites. With short TOS reactive carbonaceous deposits largely contribute to the overall isobutene production but simultaneously harm the selective catalytic action by inducing nonselective reactions. With prolonged TOS the deposits become nonreactive and accordingly isobutene is produced with high selectivity. It is demonstrated that at this stage no carbenium ions are present, which excludes the occurrence of a pseudomonomolecular reaction pathway. Additionally, Brønsted $\mathrm{OH}$ acid sites are still accessible on the extensively aged and highly selective H-FER, which indicates that these sites are responsible for the selective formation of isobutene from n-butene.

\section{ACKNOWLEDGMENTS}

We thank Dr. Tom Visser (Utrecht University) for helpful discussion. This work was financially supported by the Netherlands Organization for Scientific Research (NWO/CW 700-97-019).

\section{REFERENCES}

1. Butler, A. C., and Nicolaides, C. P., Catal. Today 18, 443 (1993).

2. Houzvicka, J., Hansildaar, S., and Ponec, V., J. Catal. 167, 173 (1997).

3. Mériaudeau, P., and Naccache, C., Adv. Catal. 44, 505 (1999).

4. van Donk, S., Bitter, J. H., and de Jong, K. P., Appl. Catal. A 212, 97 (2001).

5. Grandvallet, P., de Jong, K. P., Mooiweer, H. H., Kortbeek, A. G. T. G., and Kraushaar-Czarnetzki, B., Shell Corp., EP501677 (1992).

6. Mooiweer, H. H., de Jong, K. P., Kraushaar-Czarnetzki, B., Stork, W. H. J., and Krutzen, B. C. H., Stud. Surf. Sci. Catal. 84, 2327 (1994).

7. Xu, W.-Q., Yin, Y.-G., Suib, S. L., and O'Young, C.-L., J. Phys. Chem. 99, 758 (1995).

8. de Jong, K. P., Mooiweer, H. H., Buglass, J. G., and Maarsen, P. K., Stud. Surf. Sci. Catal. 111, 127 (1997).

9. Guisnet, M., Andy, P., Boucheffa, Y., Gnep, N. S., Travers C., and Benazzi, E., Catal. Lett. 50, 159 (1998).

10. Mériaudeau, P., Bacaud, R., Hung, L. N., and Vu, T. A., J. Mol. Catal. A 110, L177 (1996).

11. Cejka, J., Wichterlová, B., and Sarv, P., Appl. Catal. A 179, 217 (1999).

12. Seo, G., Jeong, H. S., Jang, D.-L., Cho, D. L., and Hong, S. B., Catal. Lett. 41, 189 (1996).

13. Houzvicka, J., and Ponec, V., Ind. Eng. Chem. Res. 36, 1424 (1997).

14. Asensi, M. A., and Martinez, A., Appl. Catal. A 183, 155 (1999).

15. Seo, G., Kim, M.-Y., and Kim, J.-H., Catal. Lett. 67, 207 (2000).

16. Brouwer, D., and Oelderik, J., Recl. Trav. Chim. Pays-Bas 87, 1435 (1968).

17. Guisnet, M., Andy, P., Gnep, N. S., Travers, C., and Benazzi, E., J. Chem. Soc., Chem. Commun., 1685 (1995).

18. Andy, P., Gnep, N. S., Guisnet, M., Benazzi, E., and Travers, C., J. Catal. 173, 322 (1998).

19. Hershkowitz, F., and Madiara, P. D., Ind. Eng. Chem. Res. 32, 2969 (1993).

20. Chen, D., Gronvold, A., Rebo, H. P., Moljord, K., and Holmen, A., Appl. Catal. A 137, L1 (1996).

21. Bystrov, D. S., Zeolites 12, 328 (1992).

22. Pelmenschikov, A. G., van Santen, R. A., Jänchen, J., and Meijer, E., J. Phys. Chem. 97, 11071 (1993). 
23. Jolly, S., Saussey, J., and Lavalley, J. C., Catal. Lett. 24, 141 (1994).

24. Kotrla, J., and Kubelkova, L., Stud. Surf. Sci. Catal. 94, 509 (1995).

25. Zecchina, A., Geobaldo, F., Spoto, G., Bordiga, S., Ricchiardi, G., Buzzoni, R., and Petrini, G., J. Phys. Chem. 100, 16584 (1996).

26. Lercher, J. A., Gründling, C., and Eder-Mirth, G., Catal. Today 27, 353 (1996).

27. Wichterlová, B., Tvaruzková,Z., Sobalik, Z., and Sarv, P., Microporous Mesoporous Mater. 24, 223 (1998).

28. Pazé, C., Zecchina, A., Spera, S., Spano, G., and Rivetti, F., Phys. Chem. Chem. Phys. 2, 5756 (2000).

29. Yamdagni, R., and Kebarle, P., J. Am. Chem. Soc. 98, 1320 (1976).

30. Zholobenko, V. L., Lukyanov, D. B., Dwyer, J., and Smith, W. J., J. Phys. Chem. B 102, 2715 (1998).
31. Domokos, L., Lefferts, L., Seshan, K., and Lercher, J. A., J. Mol. Catal. A 162, 147 (2000).

32. Trombetta, M., Busca, G., Rossini, S., Piccoli, V., Cornaro, U., Guercio, A., Catani, R., and Willey, R. J., J. Catal. 179, 581 (1998).

33. Finelli, Z. R., Querini, C. A., Figoli, N. S., and Comelli, R. A., Appl. Catal. A 187, 115 (1999).

34. Pazè, C., Sazak, B., Zecchina, A., and Dwyer, J., J. Phys. Chem. B 103, 9978 (1999).

35. Wichterlová, B., Zilkova, N., Uvarova, E., Cejka, J., Sarv, P., Paganini, C., and Lercher, J. A., Appl. Catal. A 182, 297 (1999).

36. Mériaudeau, P., Vu, T. A., Hung, L. N., and Szabo, G., J. Catal. 169, 397 (1997).

37. Domokos, L., Lefferts, L., Seshan, K., and Lercher, J. A., J. Catal. 197, 68 (2001). 